Sadana, J. C. \& Ahmad, B. (1947). Indian 7. med. Res. 35, 81.

Scheunert, A. \& Wagner, K. H. (1940). Biochem. Z. 303, 208.

Scoular, F. I., Bellew, J. E., Carl, C. J. \& Dozier, V. (1943). F. Amer. diet. Ass. 19, 428.

Smith, M. C. \& Otis, L. (I941). Food Res. 6, I43.

Wagner, K. H., Günther, L. \& Schmalfuss, H. (I943). Vitamine und Hormone, 4, I42.

Wagner, K. H., Günther, L. \& Schulze, L. (1941). Vitamine und Hormone, I, 455.

Werner, H. O. (1 940). Proc. Amer. Soc. hort. Sci. 38, 267.

Wilkinson, H. (r94I). Biochem. F. 35, 824 .

Wilson, H. E. C., Ahmad, B. \& Majumdar, B. N. (1936). Indian F. med. Res. 24, 399.

Wilson, R. H., Ambrose, A. M., DeEds, F., Dutton, H. J. \& Bailey, G. F. (1946). Arch. Biochem. 10, $13 \mathrm{I}$.

Wilson, R. H., Thomas, J. O. \& DeEds, F. (1943). F. Amer. diet. Ass. r9, 428.

With, T. K. (1940). Absorption, Metabolism and Storage of Vitamin A and Carotene. Copenhagen: Einar Munksgaard.

With, T. K. (1942). Vitamine und Hormone, 2, 369.

\title{
Haemoglobin Levels in Pregnancy
}

\section{The Effect of the Rationing Scheme and Routine Administration of Iron}

\author{
BY LUCY WILLS, GLADYS HILL, KAITILIN BINGHAM, \\ MARGARET MIALL AND JOAN WRIGLEY \\ Obstetrical and Pathological Departments, Royal Free Hospital, London
}

(Received I9 April I947)

It has been a medical commonplace for many years that women frequently suffer from a mild degree of anaemia during pregnancy. The anaemia is often referred to as 'physiological' and thought to be associated with the hydraemia which has been shown to occur at this time (Dieckmann \& Wegner, 1934; Thompson, Hirscheimer, Gibson \& Evans, 1938). This theory of a 'physiological' anaemia of pregnancy was based on work on hospital patients who, broadly speaking, were seldom in optimal health, and for some time we had considered the possibility that in the really well-fed woman this anaemia might be absent or negligible. Wartime conditions, by the introduction of the general rationing scheme and particularly by the introduction of special rations for pregnant women, had improved the diet of expectant mothers, especially those of the hospital class. But, though the diet of these women had improved by the end of 1943 , it was still considered low in iron judging by the number of pregnant women with hypochromic anaemia. In order, therefore, to investigate this question of anaemia in pregnancy further, an experiment was started at the end of I943 planned to show the effect on the haemoglobin level and on the general health of the pregnant woman, not only of the improved rations but also of the routine administration of iron. At the same time a fuller blood examination and serial serumprotein estimations were to be done on some of the cases. Unfortunately, a flying bomb incident interrupted the work, but, though the actual numbers of observations were not as large as expected, they were large enough for statistical analysis and are set out briefly in the present paper. 


\section{METHODS}

The observations were made on 500 women attending the antenatal clinic at the hospital. The ages of the patients ranged from 18 to 43 years and were approximately the same with the same range in the two groups. Alternate patients were given, from the first attendance, either Blaud's capsules (not pills) $30 \mathrm{gr}$., 3 times a day (approx. $0.5^{8} \mathrm{~g}$. Fe daily as ferrous carbonate), or similar capsules containing a placebo. On account of the dispersal of the patients due to the bomb incident no attempt was made to give the routine iron after delivery. It was impossible to ensure that the women took the capsules, and it is certain that the 'treated' series included many women who, in fact, took little of the additional iron. The laboratory workers were not told which patients were receiving iron, but after a few visits it did not require a Sherlock Holmes to ascertain the nature of the capsules being taken. The cases were unselected except that nine women who had haemoglobin values below $70 \%$ associated with the blood picture of a hypochromic (iron deficiency) anaemia at their first visit, and one woman suffering from severe rheumatoid arthritis, were excluded from the series.

The women were asked to report at stated intervals to the laboratory, but, as the figures and tables show, the attendance was not regular in all cases in spite of excellent team work by the staff at the clinic and also by many of the women. The duration of treatment varied also, as some of the women did not report until after the r6th week of pregnancy. The haemoglobin was estimated by the Haldane method, the conditions laid down in the report of the Committee on Haemoglobin Surveys (r945) of the Medical Research Council being strictly observed and all apparatus used being standardized by the National Physical Laboratory. The same two observers (L.W. and K.B.) made all the readings; these two observers had worked on the M.R.C. Haemoglobin Survey and their haemoglobin readings had been shown to agree closely, so that in the present survey no correction was made for personal errors in reading. The values are expressed as percentages on the Haldane scale; $100 \%$ haemoglobin on the new N.P.L. standard being equivalent to 14.7 or $14.8 \mathrm{~g} . / 100 \mathrm{ml}$. (King, Gilchrist \& Matheson, 1944; Macfarlane \& O'Brien, 1944). As 'normal' standards for women between the ages of 18 and 43 for comparison with our findings the following values were used, though it is generally agreed that the figures on which these 'normals' are based are not necessarily satisfactory normal means, since the haemoglobin level of certain groups of apparently healthy women can be raised by iron therapy (Committee on Haemoglobin Surveys, 1945):

Haemoglobin 14.2 g./roo ml. (96\% Haldane). Range 90-104\%.

Red blood cells 4,800,000/cu.mm. Range 4,200,000-5,200,000.

Mean corpuscular volume $86 \mu^{3}$. Range 80-94 $\mu^{3}$.

Mean corpuscular haemoglobin concentration $34 \%$. Range $32-38 \%$.

The blood for serum-protein estimation and full blood-counts was also taken under the standard conditions laid down in the M.R.C. report. The protein was estimated by the Kjeldahl method; the estimations were done in duplicate or triplicate and agreed well, but a positive $6 \%$ correction has been applied to all the results. This correction factor was used as the result of a cross-check with Dr Hoch of the London Hospital 
on the results of protein estimations by the copper sulphate specific gravity method. Our results by the copper sulphate method agreed very closely with his which corresponded closely with his figures obtained by the improved Kjeldahl method. Our Kjeldahl figures showed an error of $-6 \%$, due to the fact that we had not digested the protein for a sufficiently long time. Our values for serum protein for the early pregnancy and postnatal months, when corrected, agree closely with those of Dr Hoch.

The word 'significant' is used throughout the paper in its statistical sense.

\section{RESULTS}

\section{Haemoglobin}

The haemoglobin values will be considered first. It is obvious from Tables $\mathrm{I}$ and 2 and from Fig. $I$ that there was a striking difference between the mean haemoglobin values of the women receiving iron and of those receiving the placebo. The mean

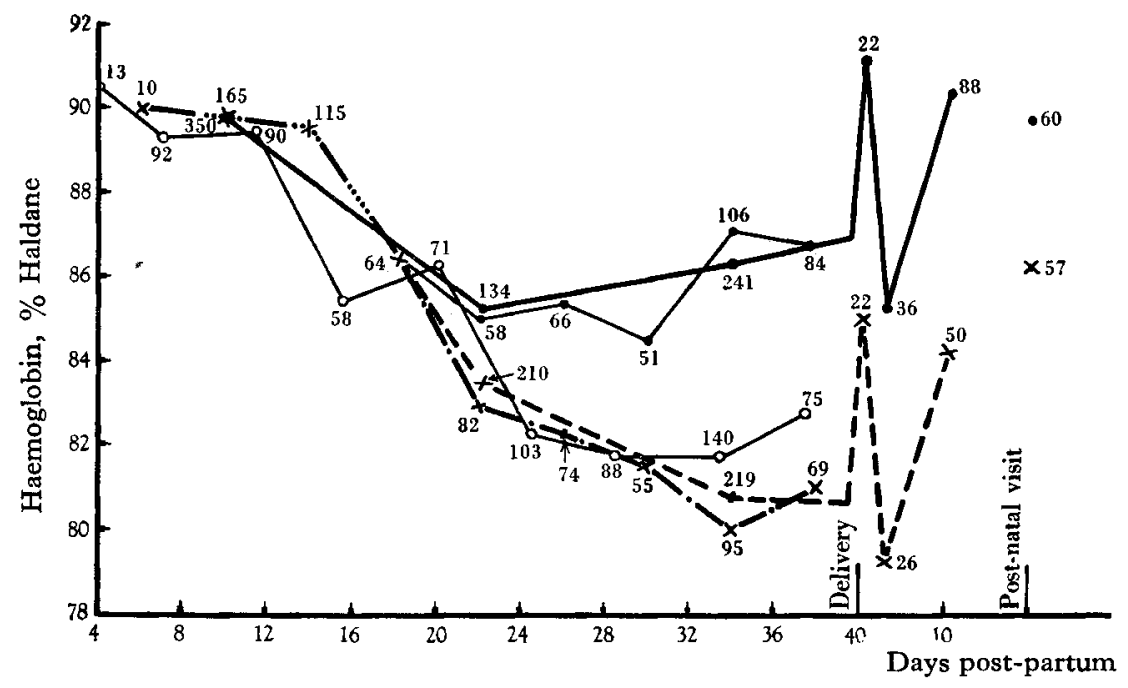

Weeks of pregnancy

Fig. I. Mean haemoglobin levels during pregnancy and puerperium of women who received or did not receive iron treatment during pregnancy (authors' series) and of unselected women (series of Committee on Haemoglobin Surveys, 1945). - - treated women, mean I2-weekly values; - - treated women, mean 4-weekly values; $x--\times$ untreated women, mean 12 -weekly values; $x-\cdot-\cdot-x$ untreated women, mean 4 -weekly values; $x-\cdots \times \cdots-\cdots \times$ combined line for treated and untreated women before iron therapy began; $O-O$ unselected women (Committee on Haemoglobin Surveys, 1945). Figures denote number of observations.

initial values for the two groups were 89.76 and $89.78 \%$ respectively and for the combined groups $89.77 \pm 0.34 \%$; the groups were, therefore, strictly comparable when treatment was commenced and the figure for the combined groups was taken as a basal level. During the 2nd trimester the mean levels for the two groups were 85.2 and $83.5 \%$ respectively, a significant fall in both from the initial mean level of $89.8 \%$, but there was already a definite and significant difference between the levels of 


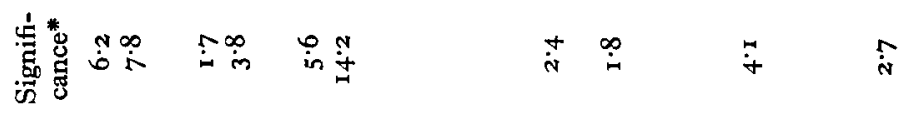

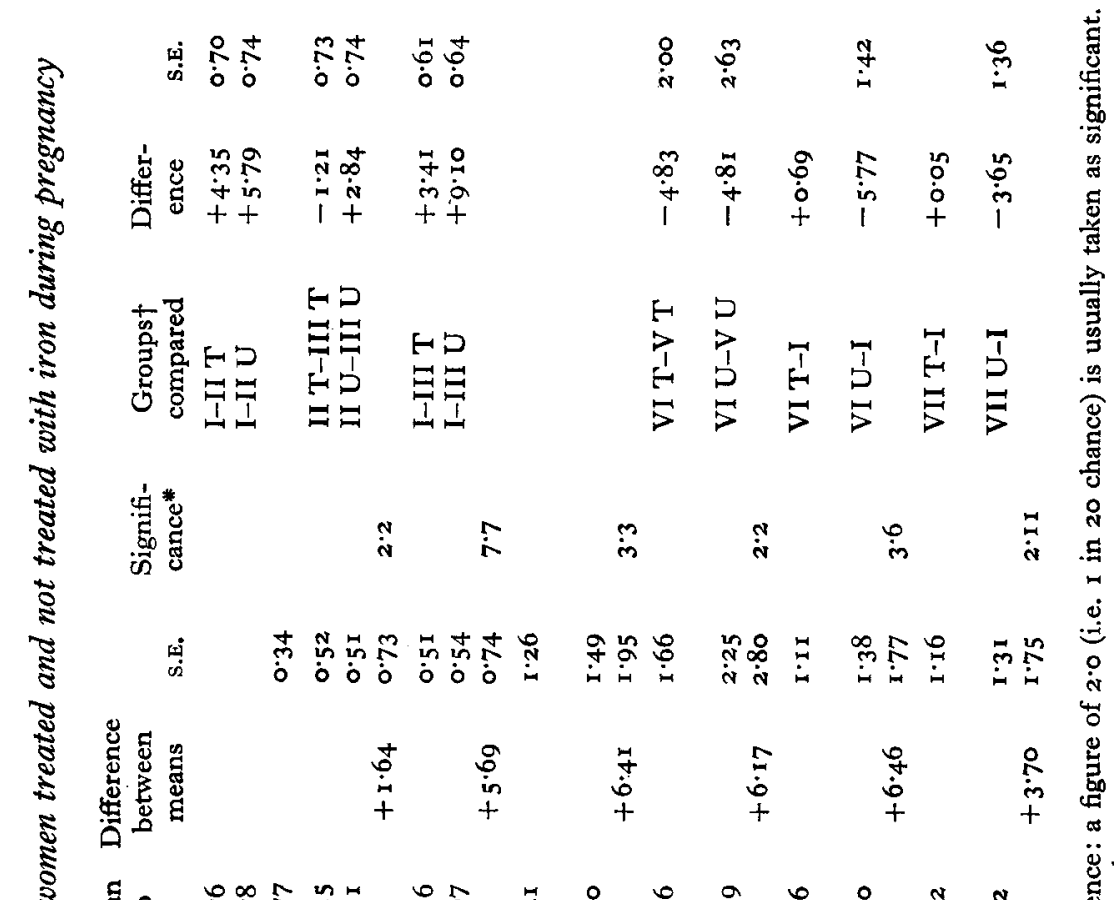

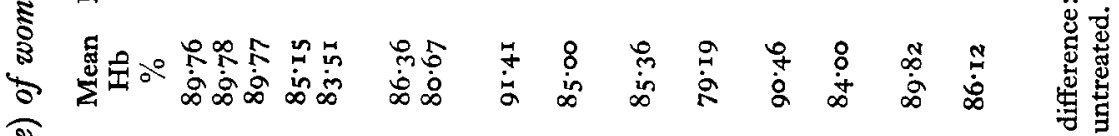

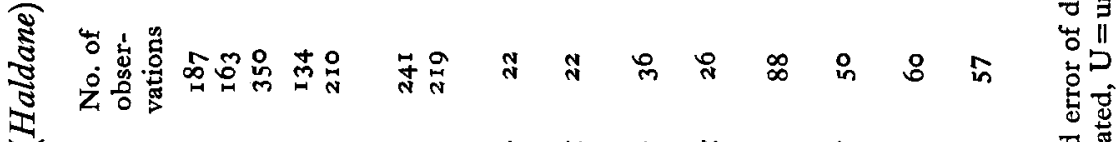

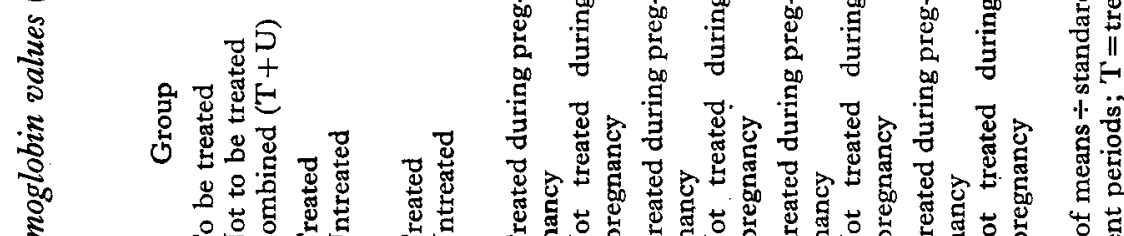

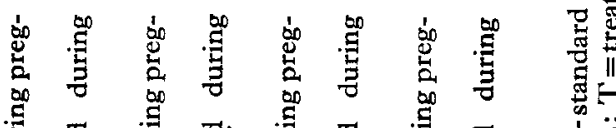
得荡焉

竎

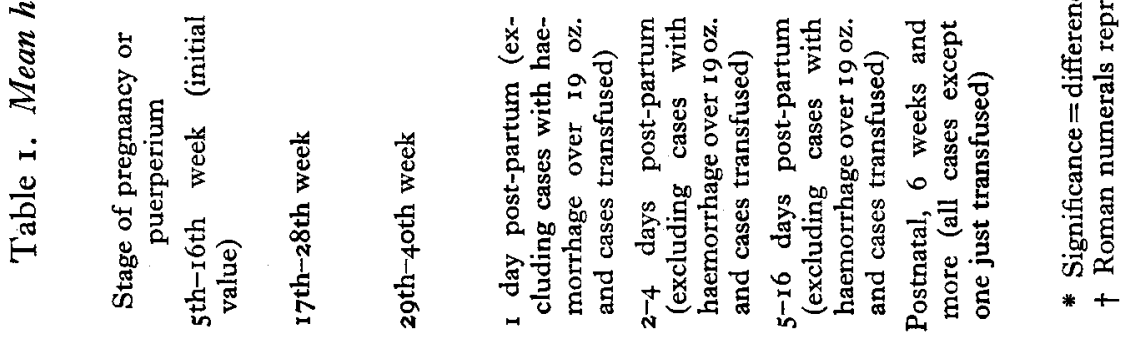
总 
the treated and untreated groups. In the $3^{\text {rd }}$ trimester the mean haemoglobin value of the treated group, $86.4 \%$, was considerably though not statistically higher than it had been in the previous period, but this value was very significantly higher than that of $80.7 \%$, the mean figure for the untreated group.

The mean values of the two groups for the $24 \mathrm{hr}$. immediately after delivery showed a marked rise which is clearly seen in Fig. I; this rise was not sustained, as by the 2nd to 4 th day post-partum the mean values for both groups were lower than the mean values for the last 4 weeks before delivery. The values for those patients who had lost more than I9 oz. of blood or had been transfused were excluded. Further studies (unpublished) have shown that the high values immediately after delivery are due to a haemoconcentration that takes place during labour and which may be very marked in certain cases. Throughout the puerperium, though the patients were then receiving identical treatment, the difference shown between the two groups persisted and was very marked in the $5^{\text {th-r }}$ 6th-day period, when the mean haemoglobin of the previously treated group was $90.5 \%$, a value very near to the initial haemoglobin value for the two groups, whereas the previously untreated group had a mean value of only $84.0 \%$, a value very significantly lower than the initial value. Finally, the mean values for the two groups at the postnatal visit, which varied in time from 6 to 12 weeks after delivery, were still significantly different, the previously treated group having a mean value of $89.8 \%$, a value identical with the initial one, but the group not treated one of only $86 . I \%$, a figure significantly lower than the initial one.

The mean haemoglobin values of the two groups were also analysed by 4-weekly periods and the values are shown in Fig. $\mathrm{I}$; these values fall on or near the lines joining the values for the trimester periods. Further analysis of the figures showed a slight but not significant rise in the mean haemoglobin value for both groups in the week before delivery.

In view of Davidson's work (Davidson, Fullerton \& Campbell, 1935) on haemoglobin values in multiparous and nulliparous women, our figures were analysed according to parity and the values are given in Table 2. In the first period, when the women had had no treatment, there was already a slight but not significant difference in favour of the group of primiparae. As pregnancy progressed, the mean haemoglobin values of all the groups fell, the treated cases showing a superiority over the untreated, the difference between treated and untreated cases being very definitely significant in both parity groups in the 3rd trimester, but in the and trimester only in the group of multiparous women. The disadvantage from which the woman of the hospital class who has borne children suffers was also shown when the result of treatment was considered in each parity group. In the 2nd trimester there was no significant difference between the mean haemoglobin values of treated primiparae and treated multiparae or between the mean value of untreated primiparae and untreated multiparae. By the 3 rd trimester iron treatment had kept the mean haemoglobin of the group of multiparous women at a level which, though lower, was not significantly different from that of the primiparous women receiving iron. In contrast, the mean haemoglobin level of untreated multiparous women was significantly lower than that of untreated primiparae. 


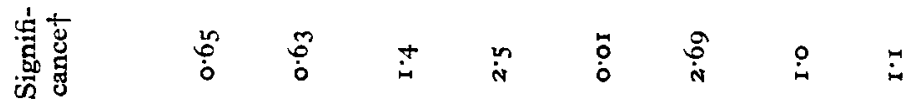

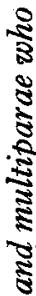

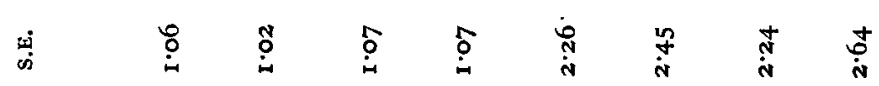

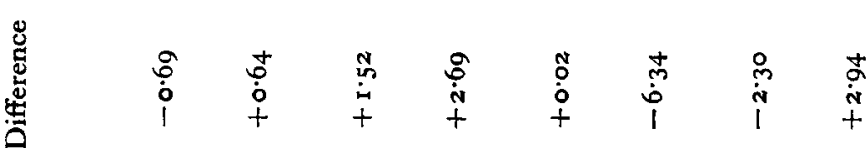

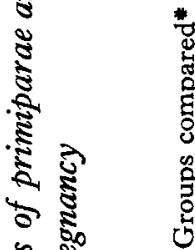

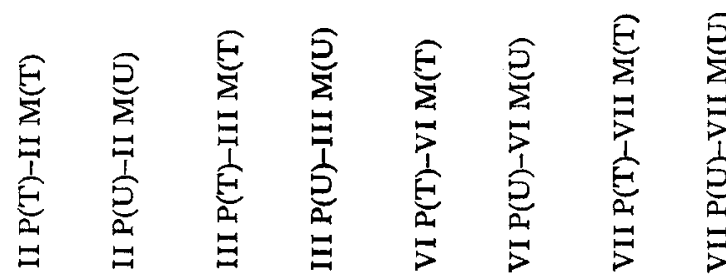

ธั

8

: $\frac{1}{8}$

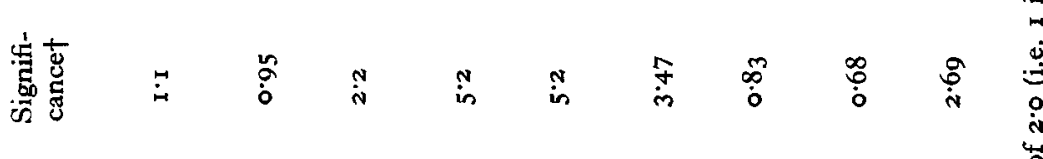

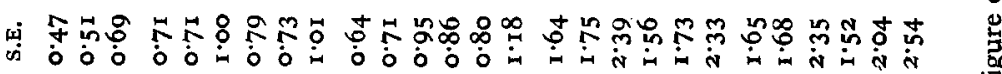

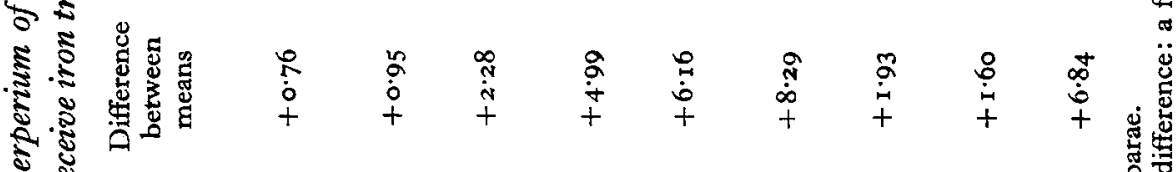

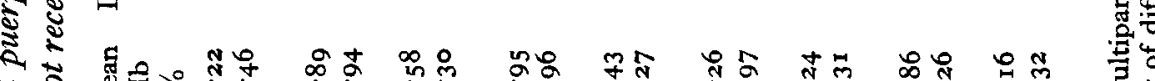
है

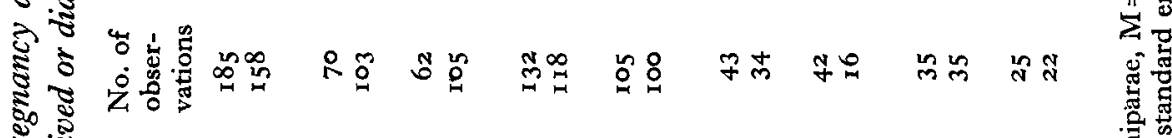

है

so

है

究

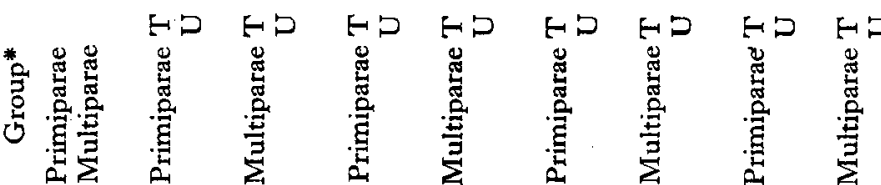

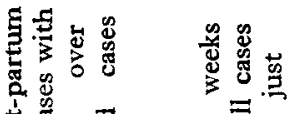
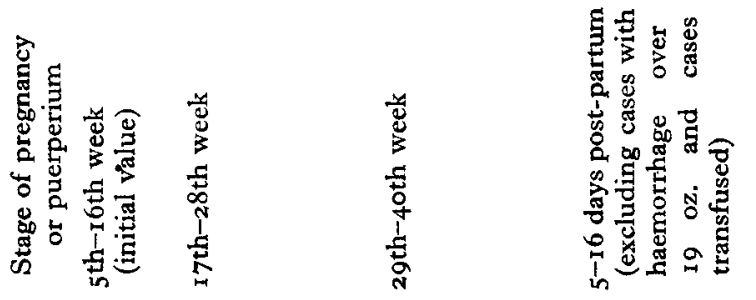

䓪

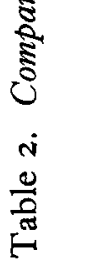

$$
\text { 总 }
$$

$\Xi$

5

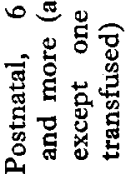

? 
Unfortunately, on account of the bomb incident, the number of cases seen after delivery was small but, with one exception, the same trend was shown in all the groups. In the post-delivery period between the $4^{\text {th }}$ and 16 th day there was the same similarity between the mean haemoglobin values of treated primiparae and multiparae and the same lowering in the mean haemoglobin value of the untreated primiparae as compared with that of the treated primiparae. But the usual difference between the treated and untreated multiparae though present was not significant, owing to the untreated cases, a small sample of sixteen cases only, having an unexpectedly high mean value. The postnatal values, if such small groups give a true picture, are of great interest, as they show the disadvantage under which untreated multiparous women remained even after delivery; in comparison with the mean haemoglobin level of $9 \mathrm{I} \cdot 2 \%$ for the treated multiparae, the untreated cases had a mean value of $84.3 \%$, a very significantly lower figure.

As already stated, patients presenting themselves at the first visit with hypochromic anaemia were excluded from the series, as it was considered almost certain that an anaemia occurring as early as the 8th-12th week must have antedated the pregnancy, and be due to causes other than pregnancy. From the remaining cases forty-four women, twenty from the treated series and twenty-four from the untreated series, were selected at random for further blood examinations, including a red-cell count, estimation of mean corpuscular volume and mean corpuscular haemoglobin concentration. The total serum protein was estimated in the same blood sample. In the majority of cases the red-cell count and haemoglobin fell as pregnancy progressed to return to normal levels at the postnatal visit, but in two cases in the treated and in two in the untreated series both the red-cell count and the haemoglobin remained at almost the same level throughout pregnancy. The average drop in the red-cell count was considerably smaller in the treated than in the untreated group. While the red-cell count and haemoglobin levels fell, the mean corpuscular volume either remained constant or increased slightly as pregnancy progressed. In no case was the mean corpuscular volume below $80 \mu .^{3}$ at any period of pregnancy or postpartum. In three cases, all in the untreated group, the mean corpuscular haemoglobin concentration fell as pregnancy progressed from normal to $29.6 \%$ in two cases and to $28.8 \%$ in the remaining case, values which suggest an underlying iron deficiency which, as judged by the colour index, was masked by the increase in mean corpuscular volume. In all the other estimations, whether these were done early or late in pregnancy, or after delivery, the mean corpuscular haemoglobin concentration lay between 30 and $38.4 \%$, with a mean figure of $33.0 \%$ for the treated series and $32.5 \%$ for the untreated series, both normal figures.

\section{Sexum protein}

The serum-protein values of treated and untreated cases are considered together, as an examination of the figures showed that there was no significant difference between the values for the two groups. This finding is in agreement with those of other workers who found that when the haemoglobin values are above $60 \%$ there is little correlation between haemoglobin levels and total serum-protein level (Committee. 
on Haemoglobin Surveys, 1945). Our figures and those of a similar series done at the London Hospital (Hoch \& Marrack, unpublished data) are shown in Table 3. The figures obtained in early pregnancy were very similar in the two series, the means for the first period being identical and for the second period showing a difference of only $0.05 \mathrm{~g}$. $/ 100 \mathrm{ml}$. After the $23 \mathrm{rd}$ week both series showed a significant fall in the mean protein level which was slightly more marked in the Royal Free Hospital series, but $4^{-16}$ days after delivery the mean figures had risen again to the level of early pregnancy.

Table 3. Serum protein during pregnancy and after delivery

\begin{tabular}{|c|c|c|c|}
\hline \multicolumn{4}{|c|}{ London Hospital series* } \\
\hline & & \multicolumn{2}{|c|}{ Serum protein } \\
\hline Stage & $\begin{array}{l}\text { No. of } \\
\text { obser- } \\
\text { vations }\end{array}$ & $\begin{array}{c}\text { Mean } \\
\text { value } \\
\text { (g./ } \\
\text { roo ml.) }\end{array}$ & $\begin{array}{c}\text { Range } \\
\text { (g. } / 100 \mathrm{ml} \text {. }\end{array}$ \\
\hline \multicolumn{4}{|c|}{$\begin{array}{l}\text { Of pregnancy } \\
\text { (weeks) }\end{array}$} \\
\hline $7-15$ & I6 & 6.92 & $6 \cdot 16-7 \cdot 74$ \\
\hline $16-23$ & 55 & 6.92 & $6 \cdot 30-7 \cdot 99$ \\
\hline $24-3 I$ & 29 & $6 \cdot 65$ & $5 \cdot 72-7.66$ \\
\hline $32-40$ & 18 & $6 \cdot 70$ & $6 \cdot 23-7 \cdot 33$ \\
\hline
\end{tabular}

\begin{tabular}{|c|c|c|c|}
\hline \multicolumn{4}{|c|}{ Royal Free Hospital series } \\
\hline & & \multicolumn{2}{|c|}{ Serum protein } \\
\hline Stage & $\begin{array}{l}\text { No. of } \\
\text { obser- } \\
\text { vations }\end{array}$ & $\begin{array}{c}\text { Mean value } \\
\text { and its } \\
\text { standard error } \\
(\mathrm{g} . / \mathrm{ro0} \mathrm{ml} .)\end{array}$ & $\begin{array}{c}\text { Range } \\
\text { (g./roo } \mathrm{ml} \text {.) }\end{array}$ \\
\hline \multicolumn{4}{|c|}{$\begin{array}{l}\text { Of pregnancy } \\
\text { (weeks) }\end{array}$} \\
\hline $8-15$ & 26 & $6.92 \pm 0.12$ & $6 \cdot 08-8 \cdot 07$ \\
\hline $16-23$ & 26 & $6.87 \pm 0.08$ & $6 \cdot 36-7 \cdot 63$ \\
\hline $24-3 I$ & 21 & $6.55 \pm 0.09$ & $5 \cdot 78-7 \cdot 50$ \\
\hline $32-40$ & 25 & $6.47 \pm 0.08$ & $5.68 \rightarrow 7 \cdot 14$ \\
\hline
\end{tabular}

After delivery

(days)

After delivery

(days)

$\begin{array}{crr}3 & 1 & 6.92 \\ 4 & 2 & 6.58 \\ 5-16 & 52 & 7.07 \\ 17-63 & 8 & 7.13\end{array}$

$$
\begin{gathered}
- \\
5 \cdot 54-7 \cdot 62 \\
6 \cdot 16-8 \cdot 40 \\
6 \cdot 74-7 \cdot 75
\end{gathered}
$$

-
4
$5^{-16}$
$42+$

$-7 \cdot 34$
$6 \cdot 98$
$7 \cdot 21$

$-5 \cdot 66-6 \cdot 46$
$6 \cdot 32-7 \cdot 78$
$6 \cdot 92-7 \cdot 48$

* Hoch \& Marrack (unpublished data).

\section{Complications of pregnancy and post-partum haemorrhage}

Records were kept of the incidence of toxaemia and other complications during pregnancy, also of nature of labour, blood loss, birth weight, immediate and neonatal mortality and puerperal morbidity rates. These records were analysed in relation to the two main groups. The incidence of toxaemia, puerperal sepsis, maternal and infant mortality was so low that an analysis of such a small series proved to be of no value. There was no difference in the mean birth weight of the two series. However, if post-partum haemorrhage is defined as any loss over $19 \mathrm{oz}$., the incidence of such haemorrhage was twenty-six cases out of 260 given iron and twenty-six cases out of 210 not given iron. This difference in the incidence of haemorrhage is not significant, but an examination of the figures for the actual blood loss in each case suffering from post-partum haemorrhage showed that the treated cases had a mean loss of $29 \cdot 0 \pm \mathrm{I}^{\circ} 59 \mathrm{oz}$. and the untreated cases one of $38.5 \pm 3.55 \mathrm{oz}$., the mean difference between the groups being significant. This difference was so striking that it was determined to examine the incidence of post-partum haemorrhage in all cases for the years 1943 and 1945 . In 1943, before our work started, iron was not given routinely to all women attending the antenatal clinic, but in 1945 every patient was prescribed 
iron. It was not possible to compare the amounts lost as the volumes were not recorded accurately in a large number of cases in 1943 . The results of the examination of the records are shown in Table 4 . There is a significant difference between the percentage incidence in the years 1943 and 1945 ; the difference for both parity groups combined would occur by chance only I in 1250 times. The same significant difference is seen in the two parity groups considered separately.

Table 4. Incidence of post-partum haemorrhage at the Royal Free Hospital

\begin{tabular}{|c|c|c|c|c|c|c|c|c|c|}
\hline \multirow[b]{3}{*}{ Year } & \multicolumn{3}{|c|}{ All cases } & \multicolumn{3}{|c|}{ Primiparae } & \multicolumn{3}{|c|}{ Multiparae } \\
\hline & \multirow{2}{*}{$\begin{array}{c}\text { No. of } \\
\text { cases } \\
\text { delivered }\end{array}$} & \multicolumn{2}{|c|}{$\begin{array}{l}\text { Incidence of } \\
\text { haemorrhage }\end{array}$} & \multirow{2}{*}{$\begin{array}{c}\text { No. of } \\
\text { cases } \\
\text { delivered }\end{array}$} & \multicolumn{2}{|c|}{$\begin{array}{l}\text { Incidence of } \\
\text { haemorrhage }\end{array}$} & \multirow{2}{*}{$\begin{array}{l}\text { No. of } \\
\text { cases } \\
\text { delivered }\end{array}$} & \multicolumn{2}{|c|}{$\begin{array}{l}\text { Incidence of } \\
\text { haemorrhage }\end{array}$} \\
\hline & & (No.) & $(\%)$ & & (No.) & $(\%)$ & & (No.) & $(\%)$ \\
\hline 43 & $\begin{array}{l}434 \\
567\end{array}$ & $\begin{array}{l}87 \\
68\end{array}$ & 20 & 272 & 57 & $21 \cdot 0$ & 162 & 30 & $\begin{array}{r}18.5 \\
0.0\end{array}$ \\
\hline
\end{tabular}

DISCUSSION

The results reported above deal with the effect, if any, on the haemoglobin level and the health of 'normal' pregnant women of rationing and the routine administration of iron. 'Normal' pregnant womer means women with no known physical disability and who, in particular, were not suffering from anaemia when they first reported to the antenatal clinic. Earlier work had shown a high incidence of low haemoglobin values among pregnant women (Committee on Haemoglobin Surveys, 1945); this anaemia was at its worst during the years of the depression and was greater among multiparae than among primiparae (Davidson, Fullerton, Howie, Croll, Orr \& Godden, 1933). The M.R.C. haemoglobin survey (Committee on Haemoglobin Surveys, 1945) showed that by 1943 the incidence in the ist trimester of cases with haemoglobin below $70 \%$, and, therefore, most probably suffering from an iron deficiency, had fallen to $1.0 \%$. In our series nine cases, four multiparae and five primiparae, or $2.6 \%$ of all cases examined before the 16 th week, had a hypochromic anaemia when first seen and were excluded from the survey.

An examination of Fig. I shows that in both series the curves of the mean haemoglobin percentages fall as pregnancy progresses but, whereas the curve for the untreated group shows a steady fall until the 36 th week and then a very slight rise before delivery, the fall in the cases of the treated group is checked at the 2oth-24th week, and thereafter the curve shows a rise until delivery. The curve for the untreated cases lies very close to that of the M.R.C. survey (see Fig. I), but the curve of the treated cases is at a higher level from the 2oth week onwards. This difference between the treated and untreated groups is very definite and statistically significant in spite of the fact that the treated group certainly included many women who did not take their iron, or only took it irregularly. The fall in the haemoglobin values in both groups was not associated with a hypochromic anaemia. Random sampling in both groups showed it to be associated with a tendency to an increase in the mean corpuscular volume, the red cells remaining well filled as judged by their appearance, the colour index and the mean corpuscular haemoglobin concentration. The tendency for the red 
corpuscles to increase slightly in size while the mean corpuscular concentration remained the same was seen in the majority of the cases whether the red-cell count and haemoglobin percentage fell, fell and rose again, or remained almost constant, throughout pregnancy. This increase in corpuscular volume has been noted by other workers (Dieckman \& Wegner, I934). The relation of the iron taken to the rise in the mean haemoglobin level in later pregnancy seen in the treated group will be discussed later but, judging from the nature of the changes in the haematological picture, it cannot have acted by correcting a latent hypochromic anaemia.

If it is assumed that the progressive increases in blood and plasma volume, which have been shown to occur as pregnancy proceeds, are a constant finding in all untreated cases, can the relatively greater increase in plasma volume as compared with blood volume, account entirely for the fall in the haemoglobin percentage seen in the later months of pregnancy, and is this 'anaemia' physiological? Does iron by arresting this fall give rise to an abnormal condition or correct an abnormal one? These questions can only be answered finally by a comparison of results of blood-volume measurements and of other haematological estimations on a series of really well-fed women, women of the so-called privileged classes, some receiving and some not receiving routine iron treatment from the very beginning of pregnancy, with the results of the same estimations on another series of women of the under-privileged class, the two series corresponding in age, parity and other respects. Further, there must be a statistical analysis of the incidence of toxaemia, post-partum haemorrhage, anaemia in the children, mortality rates, and so on, in the two groups, to assess the significance of higher haemoglobin values. This work remains to be done, but the results reported above have some bearing on the subject and a review of the literature is also of interest.

Successive surveys have shown that the mean haemoglobin values during pregnancy have been rising with improvement in economic conditions; in Aberdeen in 1935 (Davidson et al. 1935 ) they were below $80 \%$ after the 4 th month, and in Edinburgh in 1942 (Davidson, Donaldson, Lindsay \& McSorley, 1943) the mean value from the 2nd month onwards was below $80 \%$, yet in 1943 the mean haemoglobin level of similar pregnant women (M.R.C. survey and our own untreated series) never fell below $80 \%$ at any time during pregnancy. Further, Davidson, Donaldson, Lindsay \& Roscoe (1944) have shown that the average haemoglobin level of pregnant women from the same antenatal clinics had risen by about 10\% between 1942 and 1944 . Fullerton, Mair \& Unsworth (1944) report a similar but smaller rise in Aberdeen.

It is generally conceded that during the war the diet of the population as a whole improved in comparison with that of the years before the war, and the improved haemoglobin levels of certain classes are usually related to this improvement. Was there any similar improvement or an alteration in the diet between 1942 and 1944 to account for the rising haemoglobin level of pregnant women mentioned above?

Davidson et al. (1944) stress the importance of the introduction during this period of National Wheatmeal flour, which gave an increased intake of calcium, iron and the vitamin $\mathrm{B}$ complex. But other important changes had also taken place in the same period. Wage rates had overtaken the cost of food in 194I, and the cost of living in 1942 , and the numbers of unemployed had fallen from 230,400 in 1941 to 54,200 in 
1944. Such changes must indicate a rise in the standard of living of the population generally. Moreover, important specific changes in the diet of the pregnant woman had taken place. In October I94I the Milk Supply Scheme guaranteed a pint of milk a day to the pregnant woman, and in the autumn of that year the Vitamin and Egg Priority Schemes were also introduced. Finally, in July I943, the pregnant woman became entitled to an extra half-ration of meat. These additions to her diet, as well as the introduction of National Wheatmeal flour, made the diet of 1944 superior to that of $194 \mathrm{I}$; they would appear to be important factors in raising the mean haemoglobin level of the pregnant woman in defiance of the increasing difficulties of the housewife.

It would, therefore, appear that with improving conditions the haemoglobin level of women both before and during pregnancy gets higher and higher and that the 'anaemia' of pregnancy gets less and less severe, but some degree of hydraemia is still not excluded as all surveys show some fall in the haemoglobin level as pregnancy progresses.

In our series certain women had constantly high haemoglobin values throughout pregnancy. Such cases were more frequent in the treated group but some were found among women who received no iron supplement. These findings argue against an hydraemia. It can also be argued that the upward trend in the curve of the mean haemoglobin values of treated cases is due to a delayed stimulation by the iron of the output of cells and haemoglobin rather than to the iron correcting an hydraemia (Widdowson, I939).

In her series of iron-treated pregnant women Widdowson (1939) found that, after the withdrawal of iron, the rise in the mean haemoglobin content that had occurred in some of her cases was not sustained, the haemoglobin values dropping immediately. It is suggested from these results that the rise in the haemoglobin level after treatment may not necessarily be physiological. In our series some of the treated cases stopped their iron supplement before the end of pregnancy but the haemoglobin value did not invariably fall, the effect of cessation of treatment probably varying with the iron equilibrium of the individual.

It has been shown by Mackay (I93 I, I933) that the routine administration of iron to children of the under-privileged classes not only increased their mean haemoglobin level but also led to a lower morbidity rate. Can it be shown that the pregnant woman whose haemoglobin has been raised by the routine administration of iron is in any way better off than her 'untreated' sister? The analysis of our findings in the 469 cases followed to delivery showed no significant difference in the incidence of toxaemia, puerperal infections, mortality rates, etc., or in the birth weight of the babies in the two series, but the difference in the incidence of post-partum haemorrhage was reduced. This finding was confirmed in a much larger series of cases (Table 4). Women of the hospital class receiving iron during pregnancy suffered less from postpartum haemorrhage than women delivered under the same conditions but who had not had iron during pregnancy. The mean volume of blood lost at each haemorrhage was also significantly less in the treated than in the untreated group in our survey. The mean haemoglobin value of the women who had been prescribed iron during pregnancy was $90 \% 6$ weeks to 3 months after delivery, a value significantly better than that of 
$86 \%$, the mean figure of the untreated group. This difference is the more impressive when it is remembered that the treated groups of women undoubtedly included individuals who either did not take their iron at all, or took it quite irregularly, and that the routine administration of iron ceased at delivery. This advantage of treatment during pregnancy was particularly noticeable in the groups of multiparous women where there was a difference of $7 \%$ between the mean haemoglobin values of the treated and untreated women. These figures would suggest that the iron absorbed during pregnancy had made good any deficiencies in the amount stored at that time and drawn on by the foetus, and that in the case of the majority of the untreated group the anaemia was not physiological but due to reserves inadequate to restore the normal haemoglobin level after delivery and during the puerperium. This alone, apart from the risk of post-partum haemorrhages, would appear to justify the routine administration of iron to hospital patients during pregnancy, as every clinician and most patients would agree on the advantage of a 'normal' haemoglobin level during the strain of lactation and of new family responsibilities. To argue, as Widdowson (1939) does, that it is impossible to raise the haemoglobin value of babies and pregnant women by physiological means (without giving iron) may be only a reflexion on the diets of this country - the inadequately fed mother giving birth to a child already handicapped by inadequate stores of iron, who is fed on a diet also inadequate in iron and requires iron treatment to raise him to, and keep him on, a good nutritional level. The mother with reserves inadequate to meet the requirements of pregnancy needs medicinal iron, as time will not permit her to get enough from a diet, even if it be supplemented, during pregnancy. The results of recent surveys already mentioned support this view; the steady rise in the mean haemoglobin level of pregnant women and the decreased incidence of hypochromic anaemia in the war years coincided with a general improvement in the diet of the mother of the hospital class. The findings in individual cases in our own and other surveys, where haemoglobin values did not fall during pregnancy, suggest the same conclusion.

\section{SUMMARY}

I. A haemoglobin survey was made of two series of pregnant women, one receiving about $0.58 \mathrm{~g}$. iron daily as ferrous carbonate and one receiving a similar capsule containing no iron. Serum-protein estimations and full blood-counts were made on a limited number of cases in both series. Standard methods, as laid down by the Committee on Haemoglobin Surveys (1945), were used throughout.

2. The mean haemoglobin percentage of both series of cases fell until the 3 oth week of pregnancy; thereafter that of the treated cases rose, but that of the untreated fell until immediately before delivery, when a slight but not significant rise occurred.

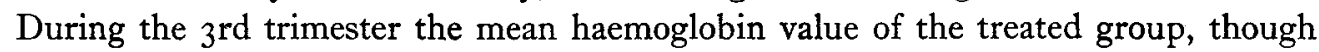
significantly lower than the initial value, was significantly higher than that of the untreated group. This difference persisted during the puerperium and was still present 6-r 2 weeks after delivery. The mean value of the treated group had returned to the initial level $5^{-16}$ days after delivery.

3. The results were also analysed according to parity. This analysis showed that 
untreated multiparous women were, throughout pregnancy and the puerperium, at a disadvantage as far as the mean haemoglobin value is concerned as compared with untreated primiparous women.

4. Complete blood counts and packed-cell volume estimations showed that the majority of cases developed a slight macrocytosis associated with a mild orthochromic anaemia.

5. The mean protein levels of the treated and untreated cases showed a significant and progressive fall after the $23^{\text {rd }}$ week until delivery, but 4-I6 days after delivery the mean figure had returned to the level of early pregnancy.

6. The incidence of toxaemia, puerperal sepsis and maternal and infant mortality was very low in both series and showed no significant difference between the two series. The incidence and severity of post-partum haemorrhage was greater in the untreated than in the treated series. This finding was confirmed in a much larger series of cases.

7. It is pointed out that the mean haemoglobin level of pregnant women has risen as economic conditions have improved.

8. The difference in the mean haemoglobin value of treated and untreated women 6-I 2 weeks after delivery, which was especially marked in the group of untreated multiparous women, suggests that the iron given during pregnancy made good a deficiency in the iron reserves and that the anaemia of the untreated group was not 'physiological', but due to inadequate iron reserves, which were insufficient to meet the demands of the foetus or to restore the haemoglobin to the mean level obtaining for both groups at the commencement of pregnancy. The fact that the mean haemoglobin level of the untreated group, unlike that of the treated group, had not returned to its initial value during the puerperium, together with the increased incidence and severity of post-partum haemorrhage in the untreated series, would appear to justify the routine administration of iron to pregnant women.

Our grateful thanks are due to Nurse Hicks and Nurse Townsend who organized the work in the antenatal clinic with the greatest efficiency and invariable good humour, and to Sister Parry of the Maternity Ward who bore with our visitations at all hours and helped in every way with the work. We are also indebted to the Maternity Department clerks for their help with the records.

\section{REFERENCES}

Committee on Haemoglobin Surveys (1945). Spec. Rep. Ser. med. Res. Coun., Lond., no. 252.

Davidson, L. S. P., Donaldson, G. M. M., Lindsay, S. T. \& McSorley, J. G. (r943). Brit. med. F. ii, 95. Davidson, L. S. P., Donaldson, G. M. M., Lindsay, S. T. \& Roscoe, M. H. (1 944). Brit. med. F. ii, 333. Davidson, L. S. P., Fullerton, H. W. \& Campbell, R. M. (1935). Brit. med. F. ii, I95.

Davidson, L. S. P., Fullerton, H. W., Howie, J. W., Croll, J. M., Orr, J. B. \& Godden, W. (I933). Brit. med. F. i, 685 .

Dieckmann, W. J. \& Wegner, C. R. (1934). Arch. intern. Med. 53, 7I.

Fullerton, H. W., Mair, M. I. \& Unsworth, P. (1944). Brit. med. F. ii, 373.

King, E. J., Gilchrist, M. \& Matheson, A. (1944). Brit. med. F. i, 250.

Macfarlane, R. G. \& O’Brien, J. R. R. (1944). Brit. med. F. i, 248.

Mackay, J. M. M. (193 I). Spec. Rep. Ser. med. Res. Coun., Lond., no. 157.

Mackay, J. M. M. (1933). Arch. Dis. Childh. 8, 221.

Thompson, K. J., Hirscheimer, A., Gibson, J. G., Jr \& Evans, W. A., Jr (1938). Amer. F. Obstet. Gynec. 36, 48 .

Widdowson, E. M. (1939). Lancet, 237, 640 . 